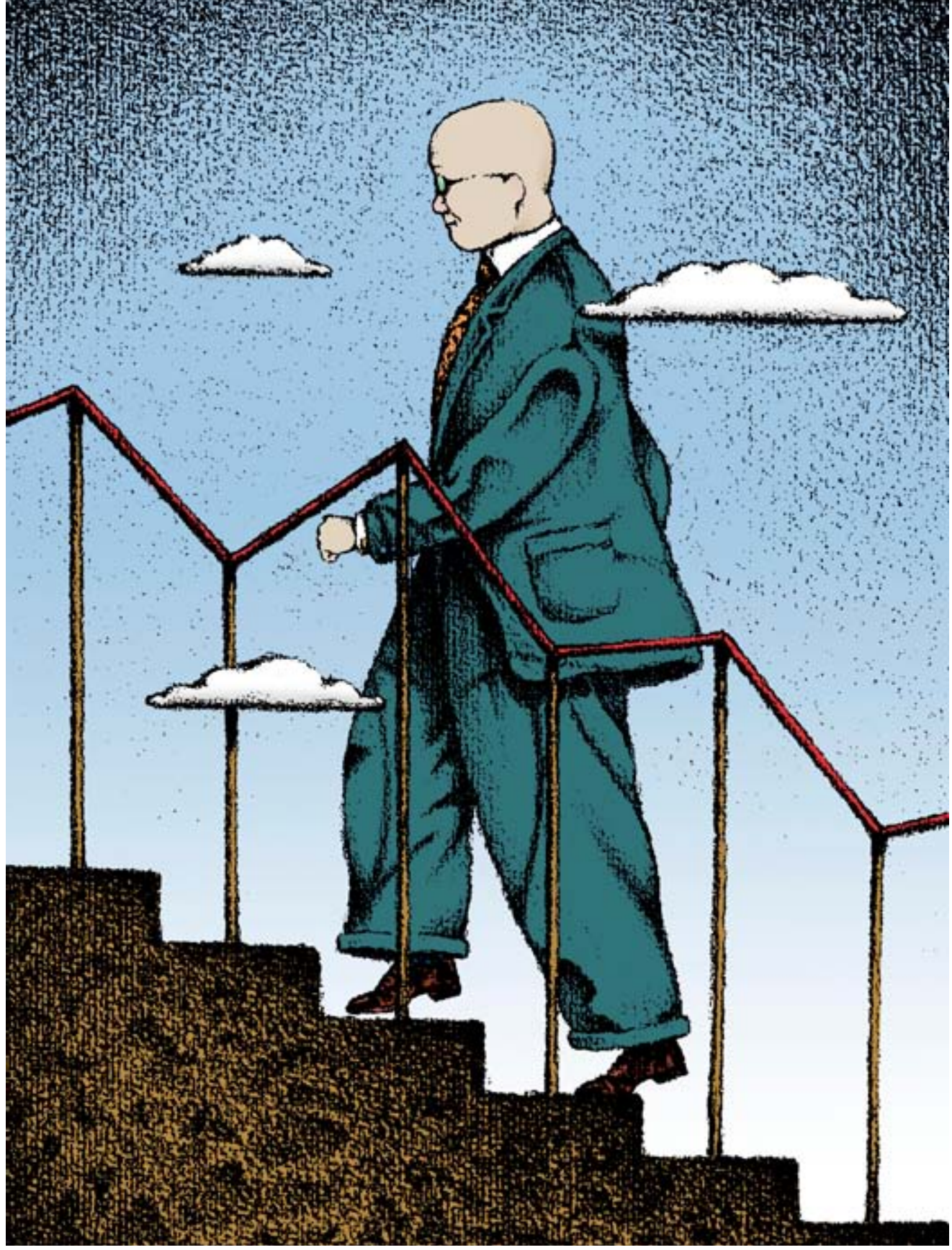

"Ph.D. en Ciencias del Trabajo,
Universidad Católica de Lovaind Universidad Católica de Lovaina,
Bélgica. Profesor Facultad Econom

\section{Las presiones y tensiones en el sistema de Alta Dirección Pública}

El sistema debutó en 2003 para garantizar que el mérito profesional, más que el partisanismo político, entrara en la alta dirección del Estado. Pero todos sabían que la prueba mayor llegaría cuando cambiara la coalición política gobernante. La prueba llegó. Y el sistema no se está fortaleciendo. Por Eduardo Abarzúa*
¿Creemos o no en un Servicio Civil para Chile? En 2003, fruto de un amplio concursabilidad para un conjunto de cargos antes de nombramiento discreciona de la autoridad politica. De esta forma se iniciaba uno de los cambios más trascendentales en la gestión de personas estramérito y de una administración profesional para un conjunto de cargos de prim y segundo nivel jerarquico. Se comenzaba a proteger una parte de la administración del Estado del cuoteo politico.

Dirección Pública recoge en su diseño Dirección Publica recoge en su diseño las sales que tiene elmundo político en su convivencia con una gerencia profesional. Para unos fue una manera de quitar facultades al ejecutivo; para otros, simplemente, perderlas. En torno a dicha dinámica se produjo el consenso que no siempre respeto el principio fundador de sistema: dotar al Estado de los mejores profesionales cuyas funciones no se liciones del gobierno de turno, sino aue se basaran en la continuidad de políticas públicas con perspectivas de largo plazo. Así nació nuestro modelo de Servicio Civil, a veces brillante y también contradictorio. Por ejemplo: el proceso es altamente exigente al momento de seleccionar, pero desprotege al gerente público a la salida porque basta la invocación de la perdida de confranza politica para de Desempino. El mundo acénvento sabia: el sistema realmente se probaria cuando cambiara el signo de la colació gobernante.

EL SISTEMA EN LA ALTERNANCIA En las últimas semanas se ha ido consolidando una relación con el sistema por parte de la actual coalición gobernante
Por ejemplo: el recurso a la pérdida de despido sin fundamento en el desempeño de aquellos directivos que fueron selecsional. Es más, en algunos casos se les ha expresado que es por la necesidad disponer de cargos a nombrar en servicios que son parte del sistema. Tal vez aso más emblemático sea el del Director del FOSIS, quien que además tenía un empeño.

Al mismo tiempo, la permanencia a jefa de asesores del Presidente en el sionó el modelo, pues dicho Consejo tebe garantizar la imparcialidad en la concursabilidad, y limitar la discreción del ejecutivo en materia de selección de los respectivos gerentes públicos. Por lo mismo, su renuncia debe hacerse efectiva $d$ "hasta que comience el proceso de entrevistas" persiste su conflicto de interés sigue influyendo, por ejemplo, en el proceso de elaboración de perfiles y revisió de antecedentes de los candidatos. Discernir más allá del propio interés o de que la ley

Nuestro modelo no sólo permite el despido por pérdida de confianza politica sino también el reemplazo por la vía de nombramiento de profesionales transitorios o provisionales. En la práctica, mechar este recurso un gobierno podria cerros concursalos, sin fundalidad de el convenio de desempeño, y nombra a la totalidad de personas basándose en la afinidad politica. Lamentablemente, al cierre de este artículo, son más de 28
altos directivos públicos los cesados en su cargo. Ellos serán reemplazados por tros, que mientras no pasen el filtro de concurso público, sólo cumplirán el
EL DEBILITAMIENTO DEL SISTEMA Y SU INSTITUCIONALIDAD

Los hechos anteriores siembran dudas respecto a la convicción de las actuales ma de Alta Direción Pública Los dichos recientes y oficiales de uno de los partidos de la coalición gobernante criticando el sistema parecen lapidarios. En los hechos, en varios aspectos se vuelve atrás en lo avanzado en los últimos años, pues se reinstala el uso politico de los cargos que el sistema identificó: se remueve y se nombra exclusivamente por razones de confianza politica, a pesar de que los ciones en los indicadores del Convenio de desempeño que establece el Servicio Civil. Hay una evidente colisión con uno de los principios fundadores: al Estado van los mejores sin importar su pensamiento político, y son elegidos por un sistema que da garantias a todos.

Del mismo modo, si los despidos continuan, sera imposible para la Dirección Nacional del Servicio Civil administrar - sos públicos producto de una de concurpor sobre lo razonable, y será legítimo el nombramiento y mantención de suplentes, con la consecuente crítica respecto a la eficacia de su labor y la necesidad de modificar su naturaleza o rol.

Tampoco es razonable que en cada de discuta la calisir de los concursos efectuados por un Dirección Públaves del Consejo de Alta Difs cas y da garantías de imparcialidad regulando y garantizando que los procesos de selección de primer nivel jerárquico mantengan independencia de criterios politicos. Si asi ocurre, se debilita el sistema y se reinstala la potestad de nomse de habia logrado introducir el principio 
bramiento, pues se trata de la aplicación de politicas
para el pais.

Discutis. tema es vital apara avanzar en mater de profesionalización y mérito. Afirmar que sería legitimo pedir la renuncia a todos los directivos seccila ros durante el gobierno de la Concertación, pues se

dad politica", es el criterio de la afinienorme esfuerzo de los integrantes del profesionales de la Dirección Naciona del Servicio Civil, la firmas nacionales e internacionales de reclutamiento y, peor aun, los miles de postulantes que han sido parte de los procesos de selección. Lo más grave es que este tipo de argumentos, construidos para legitimar una tigian el sistema. Nadie querrá ser parte de concursos públicos en los que ser seleccionado supone afinidad política, y menos aún cuando un cambio de signo en el gobierno implica remoción, independiente de los resultados obtenidos.

PROFUNDIZAR LA ALTA DIRECCIÓN

Aqui una precaución: profundizar el sistema no significa concursar todos los de un Servicio Civil durable es asegurar cruce entre la función gubernamental y la función administrativa. Si todo es concursable, el gobierno pierde las facultades mandatadas por la ciudadanía. Si nada es concursable, el gobierno pierde las her mientas para hacer su gestion eficiente. politica: en un Estado moderno el critepolitico se integra y convive con una a ción técenca y la consistencia politisaragobierno de turno.

( discutido, sobre todo cuando estamos a las puertas de una reforma integral del sistema, es la distinción entre servicios un ntre aquellos que diseñan políticas ps que las ejecutan. El asunto no es principios sino práctico: como difereny ar cargos y actores politicos de cargos Estado.

Sobre este tema la OCDE recomienda on de diferentes criterios, ermitiria dirimir que un cargo sea más olítico que profesional. Por ejemplo, la mente neutra o diferenciadora. También el rol: hay cargos directivos que se ven sometidos a una interpelación constant

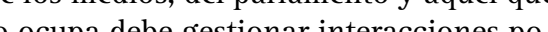
liticas delicadas y complejas. Del mismo modo, hay servicios que tienen a su cargo materias de la más alta importancia esratégica para un gobierno. En esos caso parece aconsejable la concursabilidad. Por otra parte, para aquellos servicios

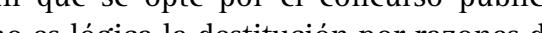
confianza política y resulta evidente que por el uso de un instrumento -el con- venio de desempeño y sus indicadores- y actuacion de la institución que ha llevireción debe ser vurciontrapeso y asegrir Esa Der un contrapeso y asegurar una blica. El rol de esta institución no es ólo garantizar la concursabilidad, sino objetividad, transparencia y excelencia en el proceso de ingreso; la apreciació del desempeño y también velar por gestión de personas en el Estado. Por 10 mismo, debiera tener el más alto rango: Otro tecra a ris la Función Pública. cos En el actual contexto, no sólo nuplentes. contrapeso al argumento de la confianze política para la cesación de un alto directivo público, tampoco existen limitaciones para nombrar un suplente. Al respeco puede ser una simple solución limita nombramiento de profesionales provisionales dejando restringida dicha desigte decerive Lo anterior senta un auténtico

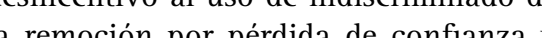
lambén un portimu a la pronta cona y abilidad de los cargos.

En los próximos días este tema estara nuevamente en discusión por la designacion en el Senado, a propuesta del Presidente de la República, de tres de los cuatro integrantes del Consejo de Alta Direcció ública. Probablemente se iniciará la discusion respecto de los cambios requeri-

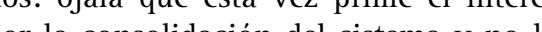
por la consolidación del sistema y no la retener o arrebatar facultades.

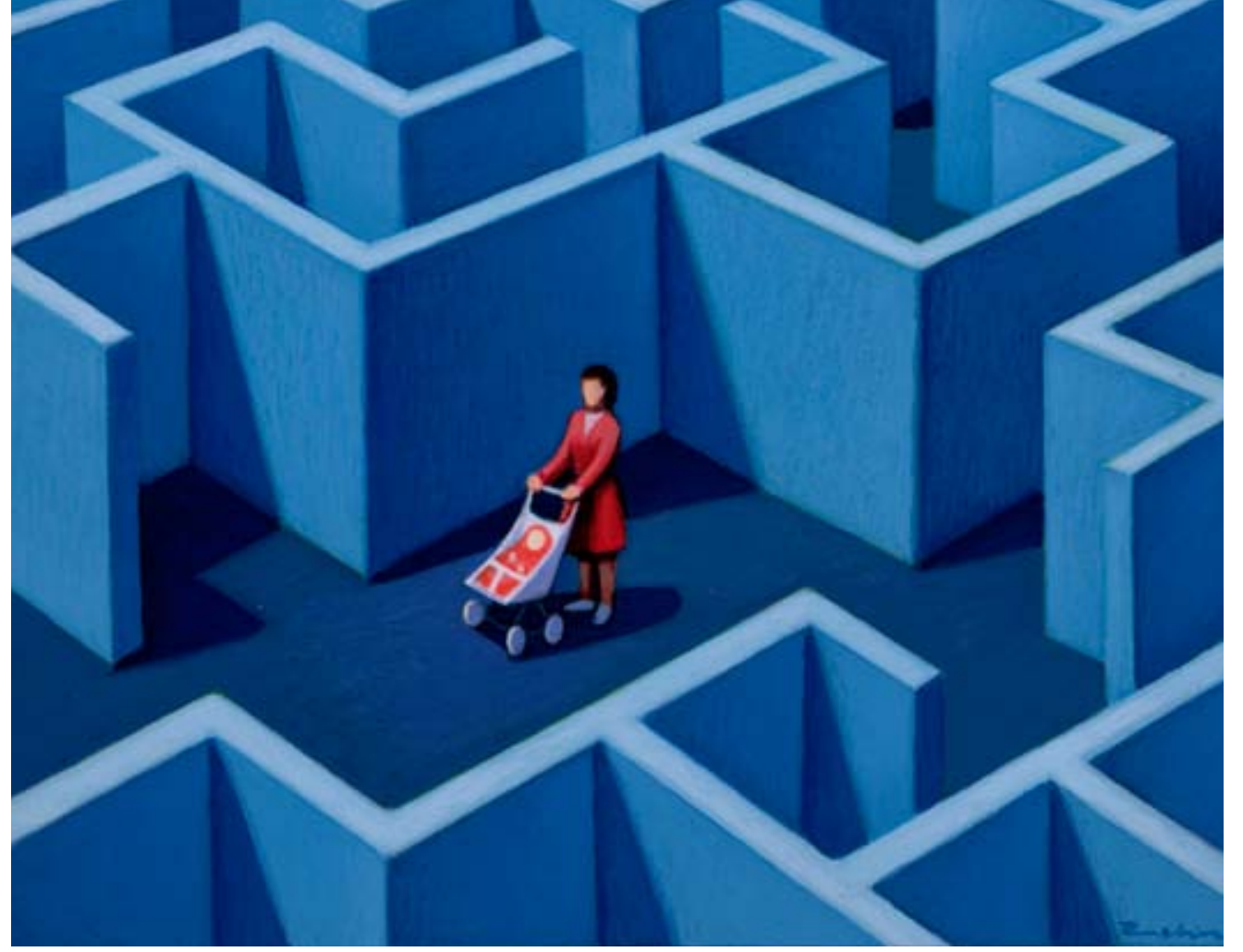

Prifesorar Facultad de Economia y Negocios,
Universidad Albert Hurtado

\section{La hora del postnatal}

Recientemente la ONG Save The Children ha publicado su indice sobre los mejores paises para "ser madre". Chile ocupa el luen desarrollo. Curiosamente, la posición de Chile en el ranking no está influida por indicadores de salud de la madre o del niño (en los cuales Chile tiene un muy buen desempeño), sino por tres indicadores: años esperados de educación formal para las mujeres, diferencial de salario por género porcentaje de puestos ocupados por mujeres en el Congreso.

Era esperable que el el debate en torno al aumento del postnatal desde 3 a 6 meses se fundamentara en la necesidad de afianzar el apego madre-hijo, incentivar lactancia materna y reducir los riesgos de contagio de enfermedades en los primeros
meses de vida. Los potenciales beneficios meses de vida. Los potenciales beneficios son muy altos y politicamente atractivos. El problema fundamental que tenemos que dillucidar como sociedad es cómo valoramios estos

Los costos de esta medida van más alla dos costos de esta medida van más alía maternal $y$ tienen que ver con el acceso de la mujer a puestos de trabajo de responsabilidad, su perfil de salarios $y$, en definitva, su capacidad de desarrollar una carrera

profesional. Hay evidencia en base a datos este periodo adicional de licencia en forma paises europeos de que si bien licencias prticipación laboral de la mujer tambien fectan negativamente los salarios $y$ la participación de las mismas en actividades de capacitación. Y justamente, en estos aspectos Chile tiene un pobre desempeño. Más aún: en la politica maternal actual, la combinación de la obligatoriedad con un un alto costo de la maternidad, justamen las mujeres con mayor nivel educativo mayor productividad.

La inserción laboral de la mujer no sólo depende de los beneficios maternales, sino

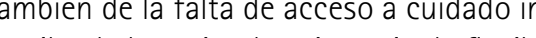

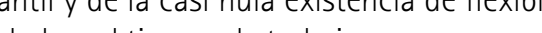
lad en el tiempo de trabajo, ya sea porque en domina una cultura de que sólo el trabajo tiempo completo es el productivo.

En el punto especifico de las licencias En eles deberían considerarse algunas meses, como por ejemplo que la extensión del postnatal fuere voluntaria o que éste pudiera traspasarse por completo o forma parcial al padre del niño. Además, madre o el padre podría optar a gozar de parcelada, previo acuerdo con su empleador. Finalmente, para mujeres afectadas por el tope del subsidio, puede evaluarse el cambiar el tope mensual por tope en la icencia total, y asi permitirles optar dentro de un menú que combine cantidad de dias de licencia pagas y topes salariales. Luego o quisieran retendrán el derecho de permacecer con licencia sin goce de sueldo hasta cumplir el tope de dias acordados por ley.

Oe

Decano: Jorge Rodriguez Grossi
Fono Facultad: 8897366 eno Facultad: irodrigu@uahurtado conomiaynegocios.uahurtado.cl/observatono Periodismo UAH. 